\title{
Solution Processable P3HT/CdS Photodiodes and Their Electrical Characterization
}

\author{
S. Meraz-Dávila, I. Chávez-Urbiola, C.E. Pérez-García, A. Sánchez-Martínez, S.A. Campos-Montiel, \\ C.G. Alvarado-Beltrán, Y.V. Vorobiev and R. Ramírez-Bon*
}

Centro de Investigación y de Estudios Avanzados del IPN. Unidad Querétaro Apdo. Postal 1-798, 76001, Querétaro, Qro., México

*E-mail: rrbon@cinvestav.mx

doi: $10.20964 / 110402962$

Received: 21 January 2016 / Accepted: 19 February 2016 / Published: 1 March 2016

In this work we apply simple layer solution deposition methods for the assembling of CdS/P3HT (poly(3- hexylthiophene)) p-n heterostructures and analyzed their photodetection properties in the visible optical range. The CdS-n layers were deposited on ITO-coated glass substrates by the chemical bath method employing an ammonia-free recipe. The P3HT-p layers were deposited on the $\mathrm{CdS} / \mathrm{ITO} /$ glass substrates by the casting method from solution by dissolving P3HT in chloroform. As the back electrodes, to complete the p-n heterostructures, carbon (graphite) was used. The electrical properties of the assembled CdS/P3HT hybrid photodiodes in dark and under illumination at several intensities, in the $0-100 \mathrm{~mW} / \mathrm{cm}^{2}$ interval, were analyzed from current density versus voltage $(J-V)$ measurements, in the $-5 \mathrm{~V}$ to $5 \mathrm{~V}$ bias voltage range. From these measurements, the photosensitivity of the photodiodes as a function of bias voltage was determined as $370 \mathrm{~mA} / \mathrm{W}$. The response of the photodiodes as a function of illumination intensity was determined from transient photocurrent measurements.

Keywords: photosensors; hybrid photodiodes; solution growth; chemical deposition.

\section{FULL TEXT}

(C) 2016 The Authors. Published by ESG (www.electrochemsci.org). This article is an open access article distributed under the terms and conditions of the Creative Commons Attribution license (http://creativecommons.org/licenses/by/4.0/). 